\title{
Perspective
}

PERSPECTIVE Actualité en histoire de l'art

$1 \mid 2020$

Japon

\section{De la Voie des esprits démoniaques à la Voie des titans. Reconsidération sur les peintures talismaniques}

From the Way of the Demon Spirits to the Way of the Titans. Reconsiderations of Talismanic Paintings

Vom Weg der dämonischen Geister zum Weg der Titanen. Eine Neubetrachtung der talismanischen Gemälde

Dalla Via degli spiriti demoniaci alla Via dei titani. Riconsiderazioni sulle pitture talismaniche

Del Camino de los espíritus demoniacos al Camino de los titanes: una reconsideración sobre las pinturas talismánicas

\section{Satomi Yamamoto}

Traducteur : François-Karl Gschwend

\section{(2) OpenEdition}

\section{Journals}

\section{Édition électronique}

URL : http://journals.openedition.org/perspective/18343

DOI : 10.4000/perspective. 18343

ISSN : 2269-7721

\section{Éditeur}

Institut national d'histoire de l'art

\section{Édition imprimée}

Date de publication : 5 juin 2020

Pagination : 167-188

ISBN : 978-2-917902-89-9

ISSN : $1777-7852$

\section{Référence électronique}

Satomi Yamamoto, « De la Voie des esprits démoniaques à la Voie des titans. Reconsidération sur les peintures talismaniques », Perspective [En ligne], 1 | 2020, mis en ligne le 30 décembre 2020, consulté le 25 janvier 2021. URL : http://journals.openedition.org/perspective/18343 ; DOI : https://doi.org/ 10.4000/perspective. 18343 


\title{
De la Voie des esprits démoniaques à la Voie des titans
} Reconsidération sur les peintures talismaniques

\author{
Yamamoto Satomi
}

\section{Remarques préliminaires}

En Chine, dans la péninsule Coréenne et au Japon, diverses entités sont appelées "démons " (jp. oni; ch. gui; co.gwi 鬼). À l'origine, le sinogramme oni 鬼 faisait référence à l'esprit (jp. tamashii; ch. hun : co. hon 魂) d'un défunt. Parallèlement aux esprits paisibles, il existe également des esprits déchaînés, ivres de haine et de colère, qui menacent les vivants. C'est pour cette raison que lorsque les canons bouddhiques (sk. sūtra) furents traduits en chinois, le terme sanskrit prata, qui désigne les morts, fut retranscrit à l'aide du sinogramme du démon. Les titans (sk. ashura), les musiciens célestes (sk. gandharva) et d'autres divinités indiennes antiques furent également appelées « esprits démoniaques " ou "divinités démoniaques" (jp. kishin; ch. guishen 鬼神) lorsqu'elles évoluèrent en des divinités protectrices du bouddhisme ${ }^{1}$. À cette liste s'ajoutent encore les entités portant atteinte à la loi bouddhique que sont les ogres (sk. yakșa) ou les goules (skt. rākșasa), et dont les noms se virent eux aussi traduits par le terme général d' « esprits démoniaques " ou de "mauvais démons " (jp. akki; ch. egui 悪鬼). En d'autres termes, $c^{\prime}$ est à travers les canons bouddhiques traduits en langue chinoise qu'apparut, en Chine et dans le Japon antique et médiéval alors sous influence culturelle chinoise, cette image de nature démoniaque ambivalente dotée d'une puissance surnaturelle orientée tant vers le bien que vers le mal.

Dans le présent article, nous proposerons une nouvelle interprétation de peintures démoniaques créées dans le Japon de la seconde moitié du XII e siècle en nous appuyant sur les liens qu'elles entretiennent avec la Voie des esprits démoniaques, basée sur les canons bouddhiques. Dans le Japon antique et médiéval, les démons étaient craints en tant qu'entités provoquant désatres et épidémies, et semant le désordre dans le monde humain. Mais si l'on porte attention aux canons bouddhiques, on voit également s'esquisser une image de démons misérables, souffrant des combats avec leurs semblables ou des malédictions de Bouddha. Jadis, les Japonais portaient attention à cette double nature des démons, et en leur vouant des cultes comme ils l'auraient fait vis-à-vis de divinités, ils les firent évoluer en des entités dignes de confiance protégeant les humains. 
Dans la version Masuda ${ }^{2}$ du Second Rouleau des Peintures des enfers (Masuda-ke-bon jigokuzōshi otsukan 益田家本地獄草紙乙巻) $)^{3}$, nous allons identifier les traces de l'ambiguïté de ces démons recelant en eux à la fois le bien et le mal.

Pendant longtemps, la source textuelle de la version Masuda était tenue pour non identifiée. Considéré comme l'un des « rouleaux dépeignant la Voie des enfers » (jigoku-zōshi 地獄草紙) produits sous le règne de l'empereur retiré Go-Shirakawa 後白河 (1127-1192, r. 1155-1158), il est composé de cinq sections en tout, actuellement conservées au musée national de Nara, en l'espèce : le Dieu du châtiment céleste (Tenkeisei 天刑星), Sendan Kendatsuba 梅檀乾闥婆 (skt. Candana Gandharva), l'Insecte divin (Shinchū 神虫), Shōki (ch. Zhong Kui 鍾馗) et Bishamonten 毘沙門天 (skt. Vaiśravana).

L'historien de l'art Kobayashi Taichirō 小林太市郎 (1901-1963) a tenté de déterminer le thème général de cette œuvre en s'appuyant sur des documents chinois. Selon lui, les cinq sections actuellement conservées dériveraient de représentations de chimères, sortes de lions ailés bienfaisants (jp. hekija, ch. bixie 辟邪, littéralement : « qui expulse le mal, talismanique "), à la mode sous la dynastie des Tang (618-907), et à l'origine des motifs de bon augure 4 . Avec le temps, ces images auraient fini par constituer un genre appelé " peintures talismaniques " (hekija-e 辟邪絵), genre confondu plus tard avec celui des peintures des enfers et dans l'évolution duquel les " assemblées des noms de Bouddha " (butsumyō-e 仏名会) - un rituel de repentance organisé chaque année au douzième mois à la cour impériale durant l'époque de Heian (794-1185) - aurait joué un rôle de premier plan.

L'historien de l'art Fukui Rikichirō 福井利吉郎 (1886-1972) propose une hypothèse opposée à la théorie de Kobayashi. En effet, il s'appuie sur le fait que chacune des sections de la version Masuda représente l'extermination d'un ou de plusieurs démons pour interpréter ces dernières comme des "peintures dépeignant la Voie des animaux " (chikushō-e 畜生絵) ${ }^{5}$. À titre d'argument, il fait remarquer que les représentations de la Voie des animaux offertes par certaines "peintures des Six Voies " (rokudō-e 六道絵) conservées à partir de l'époque de Kamakura (1185-1333) illustrent le triomphe du plus fort et, en l'occurrence, la victoire finale des démons. Il interprète donc la version Masuda comme la scène finale de la Voie des animaux, dans la mesure où elle figure des créatures tourmentées par plus puissants qu'elles. Cependant, dans les peintures des Six Voies réalisées par la suite, on n'observe aucun exemple dans lequel la Voie des animaux serait dépeinte de la même façon que dans la version Masuda. C'est la raison pour laquelle la théorie de Fukui n'a pas été reprise dans les recherches ultérieures, alors que celle de Kobayashi, au contraire, fait largement consensus. Par la suite, l'historien de l'art Miyajima Shin'ichi 宮島新一 (1946-) s'est intéressé à la réception des peintures talismaniques au Japon à partir des croyances liées aux divinités Tenkeisei et Bishamonten. En tenant également compte de leurs caractéristiques iconographiques, il a souligné la proximité entre la version Masuda et le style développé par les moines de la ville de Nara, capitale impériale entre 710 et $784^{6}$.

Il y a quelques années, l'historienne de l'art Umezawa Megumi 梅沢恵 a proposé à son tour une nouvelle théorie. Selon elle, il faudrait ajouter aux cinq sections de la version Masuda une peinture intitulée le Démon chassé (Kandō no oni 勘当の鬼), conservée au musée d'art de la ville de Fukuoka, pour former une série cohérente qui constituerait une illustration en six sections de peinture des " enfers des esprits démoniaques " (kishin jigoku 鬼神地獄) ${ }^{7}$. Umezawa souligne le fait que les démons y sont représentés en proie à des tourments et des souffrances infinies, et que s'en dégage une forme de compassion envers ces créatures suppliciées, comme le suggère cet extrait du texte introductif de Bishamonten (Musée national de Nara) : "Atteint par une flèche, le démon tombe 
à terre dans de grandes souffrances ". Umezawa suggère donc que le thème principal de ces peintures serait les démons maléfiques, et non les divinités bienfaisantes. Selon sa conclusion, à vrai dire très convaincante, ces six sections de peintures ne seraient pas de nature talismanique - le bien châtiant le mal -, mais relèveraient au contraire des peintures des Six Voies dont une partie figure les souffrances des esprits démoniaques et des dieux de la pestilence.

En tenant compte des études antérieures susmentionnées, dans le présent article, nous souhaiterions poser l'hypothèse que la version Masuda et la section du Démon chassé constituent un ensemble qu'il conviendrait d'appeler Rouleau des esprits démoniaques (Kishin sōshi 鬼神草紙), consacré à cette Voie, et mettre en lumière en quoi les caractéristiques de cette œuvre seraient applicables à la Voie des titans. Mais avant d'entrer dans le vif du sujet, nous allons tout d'abord essayer de cerner le concept de Voie des esprits démoniaques présente dans le bouddhisme, puis mettre en lumière l'existence d'une doctrine considérant comme identique les démons et les titans.

\section{Théorisation des Six et des Cinq Voies}

Dans le fondement de la vision bouddhique du monde, on retrouve l'idée de transmigration des âmes, basée sur les actions que chacun a commises dans sa vie antérieure. Dans le bouddhisme, tous les êtres existant dans ce monde ont pour destinée la répétition éternelle de ce cycle de réincarnation, et même si un être est né en tant qu'humain dans sa vie actuelle, il lui est tout à fait possible de se réincarner dans une autre voie - celle des enfers (jigoku 地獄), des démons (oni 鬼) voire des animaux (dōbutsu 動物). Dans le bouddhisme du petit véhicule, qui a pris forme dans l'Inde antique, l'objectif final était de se libérer des souffrances de ces cycles de réincarnation et de devenir un bouddha à travers des pratiques ascétiques. Parallèlement, le bouddhisme du grand véhicule, qui s'est répandu en Chine et au Japon, accordait de l'importance au Salut de l'ensemble des êtres vivants souffrant de ces réincarnations, ce qui a suscité un plus grand intérêt pour le monde des cycles de transmigration des âmes ${ }^{8}$.

De nombreux canons bouddhiques (sūtra) du bouddhisme du grand véhicule expliquent le cycle de transmigration des âmes à l'aide des Six Voies de réincarnation - enfers (jigoku 地獄), esprits faméliques (gaki 餓鬼), animaux (chikushō 畜生), titans (ashura 阿 修羅), êtres humains (nin 人) et êtres célestes (ten 天) ${ }^{9}$. Cette conception s'est largement diffusée au Japon grâce au Compendium pour la renaissance en Terre pure (Ōjō-yōsh $\bar{u}$ 往生 要集) du moine Genshin 源信 $(942-1017)^{10}$. En revanche, dans les sūtra plus anciens - qui relèvent du bouddhisme du petit véhicule -, la conception largement majoritaire est celle des Cinq Voies (enfers, animaux, esprits démoniaques, êtres humains et êtres célestes), conception qui exclut donc la Voie des titans, familière au grand véhicule.

Le Sūtra du nirvāna final (Hatsunaion-gyōo 般泥洹経, sk. Parinirvāna sūtra), l'un des plus anciens textes du canon bouddhique, par exemple, mentionne nommément les Cinq Voies. En effet, à l'occasion du dernier voyage qui le mène à Kuśinagara pour y mourir, Saakyamuni s'adresse ainsi à son disciple Ānanda : " Assis, je médite, et aussitôt je vois les Cinq Voies : êtres célestes, êtres humains, enfers, animaux et esprits démoniaques ${ }^{11}$. » Un genre appelé "peintures du cycle des réincarnations dans les Cinq Voies " (goshu shōjirin-zu 五趣生死輪図) illustre de fait une telle conception. Les Miscellanées sur le Mūlasarvāstivāda Vinaya (ch. Genbenshuo yiqie youbu Pinaiye zashi 根本説一切有部毘奈耶 杂隹事, vol. XVII ${ }^{12}$ ), traduit en chinois par Yi Jing 義净 (635-713) durant la dynastie des Tang, ou encore le Mūlasarvāstivāda Vinaya (ch. Genbenshuo yiqie youbu Pinaiye 根本説一切 有部毘奈耶, vol. XXXIV ${ }^{13}$ ) recommandent d'illustrer le cycle des Cinq Voies et fournissent 
des éléments détaillés pour son iconographie. En Inde, on en trouve des exemples remontant au $\mathrm{VI}^{\mathrm{e}}$ siècle dans la dix-septième grotte bouddhique d'Ajaṇtā. Cependant, c'est la théorie des Six Voies qui s'est principalement diffusée en Chine, comme on peut le constater à travers les nombreux témoignages conservés du genre des " peintures du cycle des réincarnations ", qui figurent de fait six Voies, et non cinq. Cependant, le consensus n'était, semble-t-il, pas parfaitement établi : en effet, l'encyclopédie bouddhique intitulée Forêt de pierres précieuses dans le jardin du Dharma (ch. Fayuan zhulin 法苑珠林, vol. XXIII) cite les Registres des signes du royaume invisible (ch. Mingxiang-ji 冥祥記) ${ }^{14}$ où l'on trouve des anecdotes en lien avec le " cycle des Cinq Voies », et plus précisément avec des "peintures du cycle des réincarnations dans les Cinq Voies " ${ }^{15}$.

Il en va de même au Japon. Grâce à différents textes d'Ōe no Chikamichi 大江 親通 (?-1151 $)^{16}$, nous savons qu'un panneau représentant une "peinture du cycle des réincarnations » était accroché à la porte centrale du temple Kombu-in 興福院 de $\mathrm{Nara}^{17}$. On ignore s'il représentait Cinq ou Six Voies, mais ces témoignages permettent de faire remonter l'histoire des peintures des Six Voies au Japon à la première moitié du XII ${ }^{e}$ siècle au moins. En un mot, il est très probable que ces deux conceptions concurrentes des Six et Cinq Voies avaient pénétré le Japon dès l'époque antique. Et dans cette hypothèse, il est donc nécessaire de reconsidérer également toute une série de peintures - en l'espèce le Rouleau des enfers (qui comprend les peintures talismaniques), le Rouleau des esprits faméliques (Gaki-sōshi 餓鬼草紙) et le Rouleau des maladies (Yamai no sōshi 病 草紙) - depuis un cadre doctrinal interprétatif différent des peintures des Six Voies basées sur le Compendium pour la renaissance en Terre pure, car ce dernier ne s'est diffusé au Japon qu'au cours du Moyen Âge.

Nous allons réexaminer à présent sur cette base les peintures et les textes introductifs des six sections de la version Masuda et du Démon chassé, et étudier la possibilité que cette série illustre la « Voie des esprits démoniaques » basée sur la théorie des Cinq Voies.

\section{La version Masuda et le Démon chassé comme représentation de la Voie des esprits démoniaques}

Toutes les peintures de la version Masuda exhibent au centre de la composition une divinité bienfaisante représentée à une échelle plus importante que le reste. Cependant, un examen minutieux des démons maléfiques victimes de cette dernière permet de constater que les figures présentes dans chacune des sections sont toutes dépeintes comme des êtres ambigus, à cheval entre le bien et le mal. Or, une analyse du contenu des images et des textes introductifs permet, comme nous allons le voir, d'interpréter ce trait comme relevant de la "Voie des esprits démoniaques », également caractérisée par une telle ambivalence. Cela fait, nous pourrons donc confirmer l'hypothèse d'Umezawa Megumi sur le lien entre la peinture du Démon chassé et la version Masuda.

\section{Le Dieu du châtiment céleste (Tenkeisei, fig. 1)}

Le texte introductif de la peinture donne l'explication suivante : " Dans le monde céleste, il y a une étoile nommée Tenkeisei. Elle capture Gozu-tennō 牛頭天王, ses compagnons, ainsi que de nombreux démons de la pestilence, les met dans du vinaigre et les mange ${ }^{18}$ ". Dans les traités d'astronomie du Livre des Jin (ch. Jinshu 巠書), compilé sur ordre du règne de l'empereur Tang Taizong 唐太宗 (v. 598-649, r. 626-649), Tenkeisei est présenté comme l'un des sept satellites de Jupiter. Considérée comme sinistre, cette 


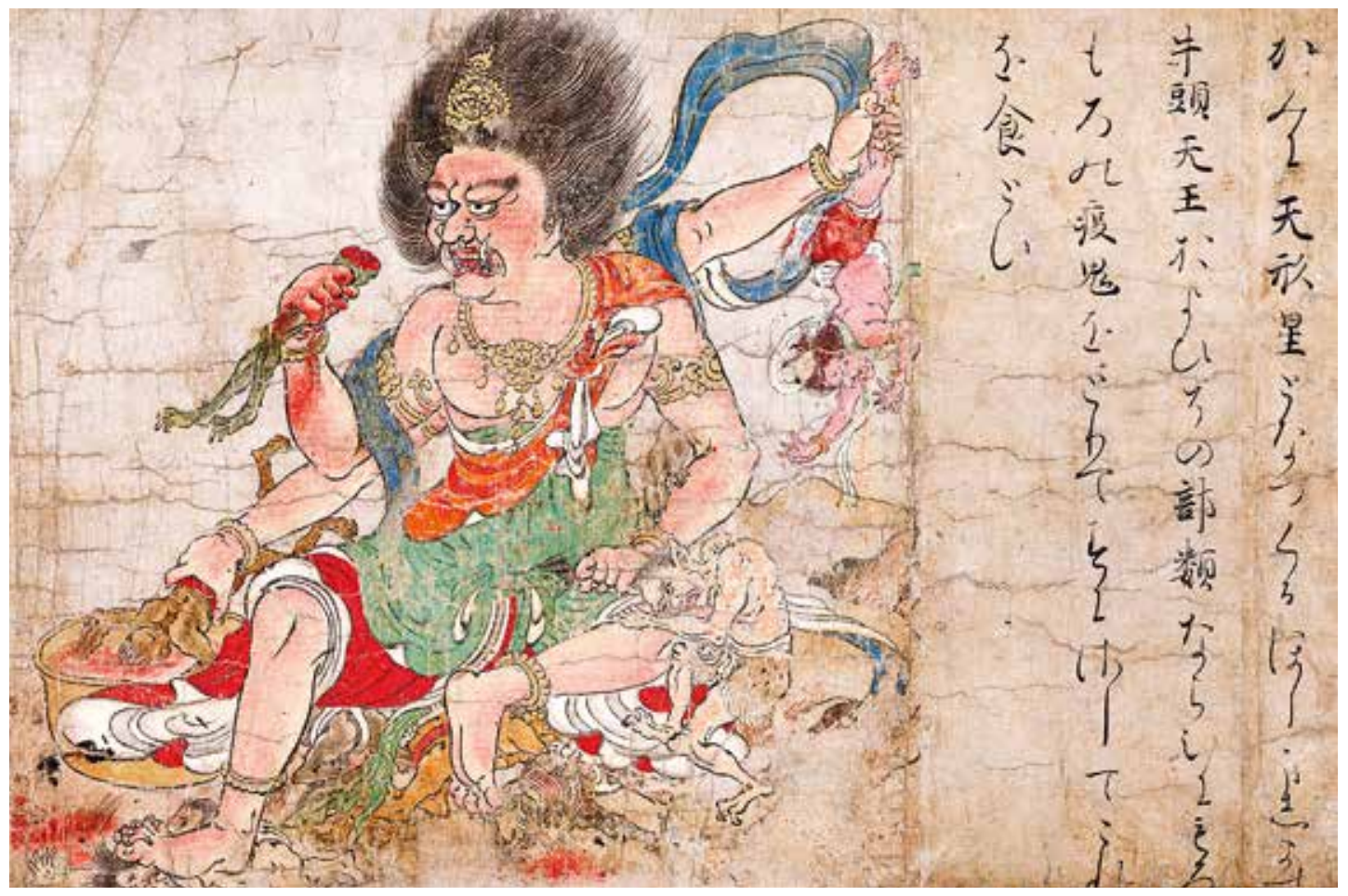

" étoile " provoquait, dit-on, inondations, sécheresses, guerres, morts, famines et guerres civiles lors de ses apparitions. À l'origine, Tenkeisei était donc redouté en tant que divinité malfaisante annonciatrice de calamités. Mais dans le Japon de Heian, il a été intégré aux esprits familiers (shikigami 式神) au service des maîtres de la Voie du ying et du yang (onmyō-ji 陰陽師 $)^{19}$. En tant que vénéré principal dans des pratiques rituelles du bouddhisme ésotérique également, il changea de nature pour devenir une divinité bienfaisante dont on attendait une protection de nature talismanique. Cependant, le texte introductif de cette section le présente comme un démon de la pestilence, et la peinture le montre, en son centre, saisissant de la main gauche les jambes d'un Gozu-tennō sur le point de succomber. Durant l'époque de Heian, cette dernière divinité fut progressivement l'objet d'un syncrétisme avec la croyance à l'origine de la fête de Gion ${ }^{20}$ et vénérée comme une puissance bienfaisante protégeant des fléaux généraux, et plus particulièrement des épidémies.

En d'autres termes, les figures de Tenkeisei et de Gozu-tennō partagent une même ambivalence : elles sont dans cette scène tout à la fois des démons redoutables et des divinités secourables. Durant la période de Heian - époque du plein épanouissement du culte de Gion -, les spectateurs d'une telle peinture étaient tout à fait conscients qu'il y avait d'autres représentations possibles de Gozu-tennō.

On trouve une ambiguïté similaire dans toutes les autres sections conservées de la version Masuda - Sendan Kendatsuba, l'Insecte divin, Shōki et Bishamonten -, ainsi que dans le Démon chassé, un point qui a d'ailleurs été fréquemment relevé dans les études précédentes. Dans son examen des sources de chacune des sections de cette ouvre, 

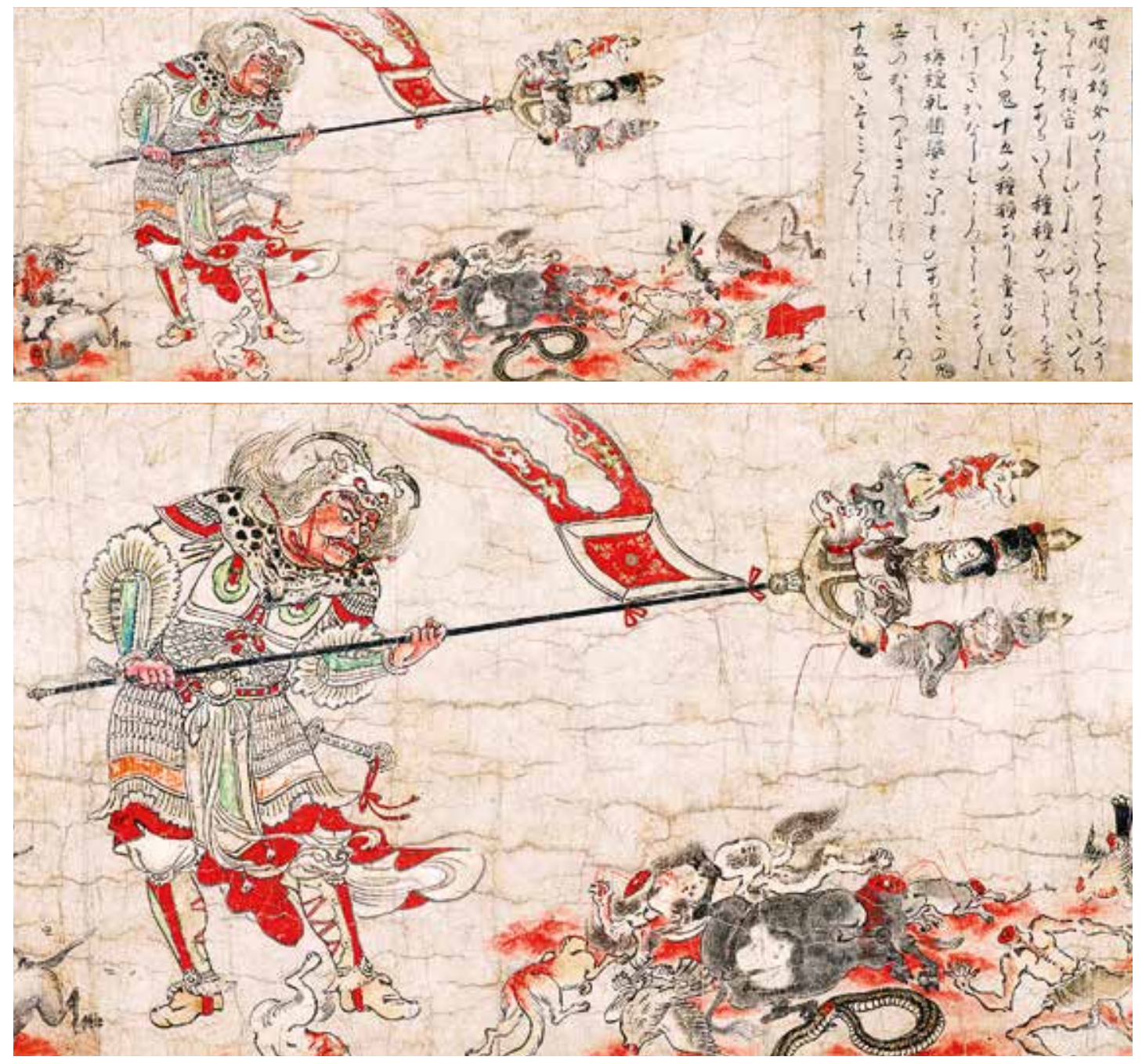

2a-b. Sendan Kendatsuba 梅檀乾䦮婆 (skt. Candana Gandharva), et un détail, Second Rouleau des Peintures des enfers (Masuda-ke-bon jigoku-zōshi otsukan 益田家本地獄草紙乙巻), fin du XII siècle, couleurs sur papier, Nara, Musée national de Nara, inv. 1106-2.
Kobayashi Taichirō a, en particulier, mis en lumière les traits spécifiques des peintures à partir des documents qu'il a étudiés de façon extensive (textes canoniques du bouddhisme et corpus anecdotique chinois). Nous allons à présent analyser les scènes suivantes en les confrontant à l'état de l'art, et tout particulièrement aux théories de Kobayashi.

\section{Sendan Kendatsuba (fig. 2a-b)}

Selon Kobayashi, la source de cette scène se trouverait dans le Sūtra de la dhārañi pour protéger les enfants (Go shodōji darani-kyō 護諸童子陀羅尼経) $)^{21}$. Dans ce texte, Sendan Kendatsuba est présenté comme le maître absolu des esprits démoniaques, régissant quinze démons ${ }^{22}$. À leur tête, Sendan Kenbatsuba retient ses acolytes par des charmes et s'efforce de protéger les enfants si on lui fait des offrandes substantielles de gourmandises, de nourriture, de fleurs et d'encens, de lumières et de brouet au lait. Il s'agit là aussi d'un exemple de démon maléfique transformé en divinité bienfaisante. 
Le texte introductif de cette section s'achève sur l'évocation de la douleur des démons vaincus et la peinture offre une représentation détaillée de leurs tourments, décapitation comprise :

Une femme de ce monde était enceinte d'un enfant. Ce dernier fut blessé dans le ventre de sa mère et mourut après sa naissance. De plus, il y avait quinze espèces de démons qui affligeaient les êtres de toutes sortes de maladies. Or, il était un être du nom de Sendan Kendatsuba qui, plein de compassion devant les offrandes, les plaintes et la douleur de la mère de l'enfant, leur coupa la tête et les planta au bout d'une lance. La souffrance des démons fut extrême.

Cette scène, dans laquelle Sendan Kendatsuba élimine des acolytes à l'origine dans le même camp que lui, permet de comprendre que son thème principal est la souffrance et l'affliction pour les partis en présence, qui relèvent tous deux de la Voie des esprits démoniaques.

\section{L'Insecte divin (fig. 3)}

Voici le texte introductif de la peinture de la troisième section : "Il existe un insecte divin qui habite dans des montagnes au sud du Jambudvīpa ${ }^{23}$. Il se nourrit d'un grand nombre de démons-tigres. Il en attrape et en dévore trois mille le matin, et trois cents le soir. " L’Insecte divin est donc présenté ici comme une divinité bienfaisante.

Kobayashi fait remarquer que des descriptions du même genre figurent dans le chapitre "Les contrées sauvages du Sud-Est " (ch. Dongnan huang-jing 東南荒経) du Classique des divinités et des choses extraordinaires (ch. Shenyi-jing 神異経), rédigé par Dongfang Shuo 東方朔 (160-93 av. J.-C.) des Han antérieurs (206 av. J.-C. - 9 ap. J.-C.). Pour être plus précis, ce dernier texte évoque une créature fantastique appelée Chikuo en chinois (jp. Shakkaku 尺廓), haute de deux mètres environ : " Elle avale trois mille démons maléfiques le matin, et trois cents le soir ", ce qui recoupe tout à fait la fin du texte introductif de la version Masuda ${ }^{24}$. Le Chikuo du Classique des divinités et des choses extraordinaires est simplement remplacé par Shinchū (insecte divin) dans cette version, substitution que Kobayashi commente de la façon suivante : «Il est possible que l'étrange nom de Chikuo, n'étant probablement plus familier aux Chinois sous les Tang, et encore moins dans le milieu de la cour impériale, ait donc été insensiblement remplacé par l'Insecte divin (Shinchū) du Jambudvipa ». En outre, il

3. L'Insecte divin (Shinchū 神虫), Second Rouleau des Peintures des enfers (Masuda-ke-bon jigoku-zōshi otsukan 益田家本地獄草紙乙巻), fin du XII siècle, couleurs sur papier, Nara, Musée national de Nara, inv. 1106-3.

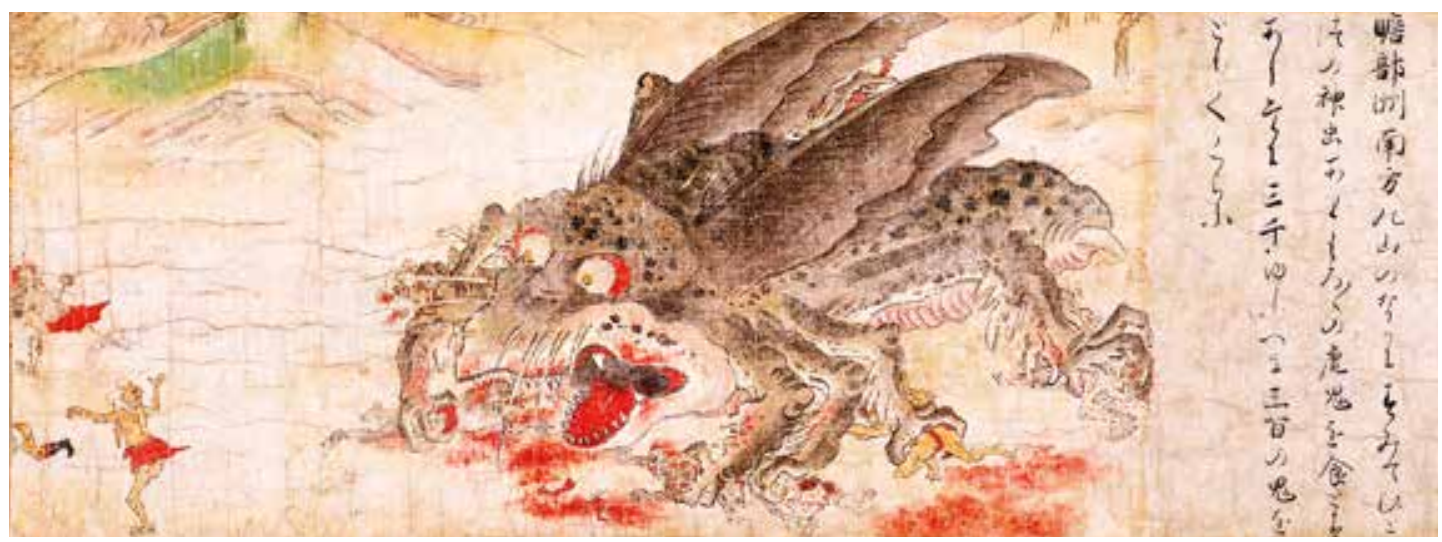




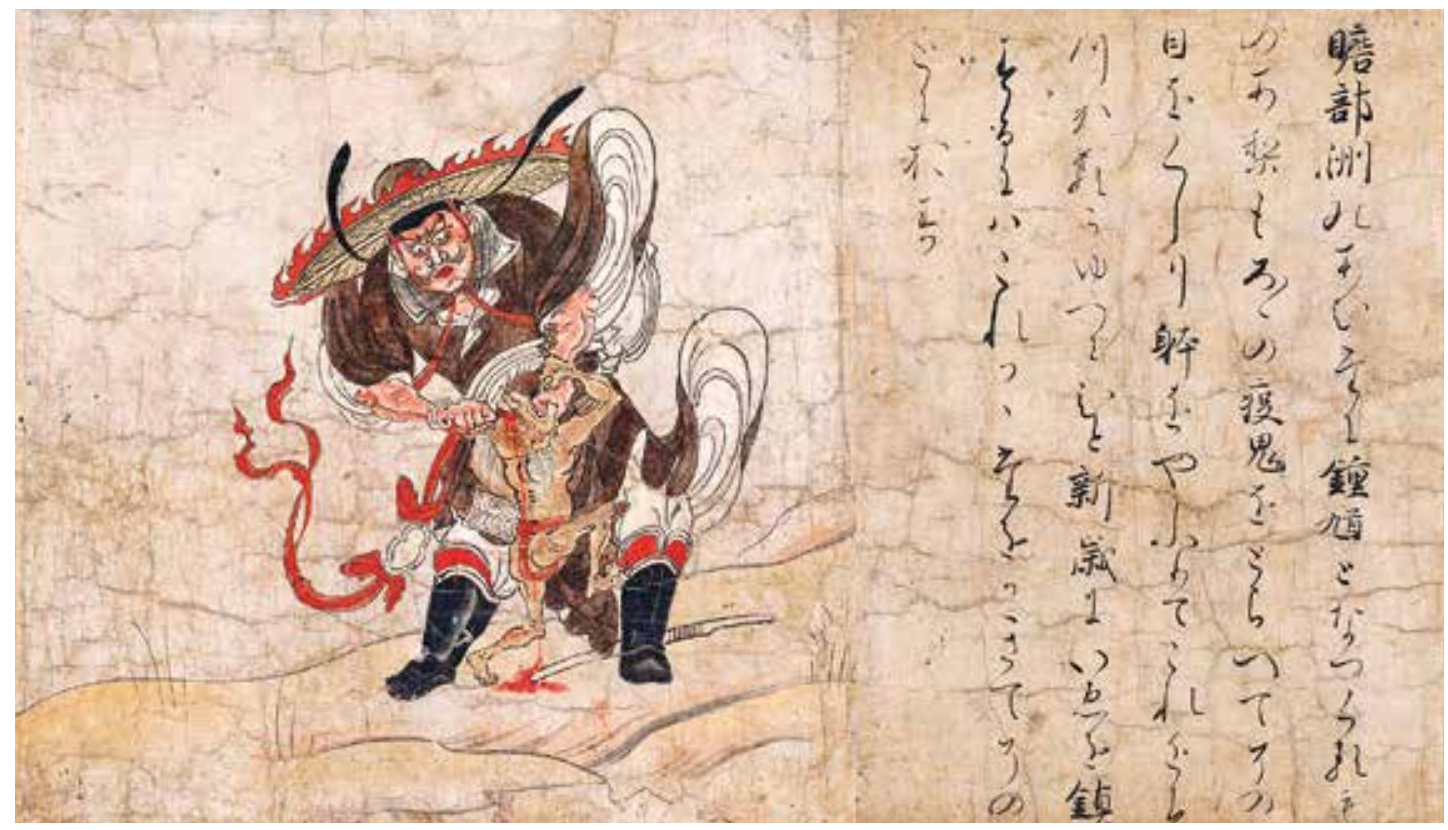

4. Shōki (ch. Zhong Kui 鍾馗), Second Rouleau des Peintures des enfers (Masudake-bon jigoku-zōshi otsukan 益田家本 地獄草紙乙巻), fin du XII siècle, couleurs sur papier, Nara, Musée national de Nara, inv. 1106-4. faut noter qu'en Chine les tigres peuvent être appelés "grands insectes" (ch. dachong 大虫). Qui plus est, Kobayashi souligne le fait que les tigres passaient pour capturer et dévorer les mauvais démons, sur la base de plusieurs sources chinoises ${ }^{25}$. En d'autres termes, nous pouvons considérer que plusieurs noyaux narratifs apparus en Chine ancienne en lien avec l'élimination de démons maléfiques finirent par fusionner, et qu'ils

se retrouvèrent au Japon dans la section sur l'Insecte divin de la version Masuda. Enfin, l'écart entre les sources chinoises (élimination des démons par des tigres) et le texte japonais (élimination de "démons-tigres " par l'Insecte divin) suggère un processus de transmission complexe de ces récits au cours duquel s'est instaurée une certaine confusion.

En outre, un examen attentif de la peinture permet de constater que le corps de l'Insecte divin est dépeint comme un ver à soie monstrueux dont la surface mouchetée évoque le pelage d'un léopard. Selon l'historien de l'art Nakano Genzō 中野玄三 (1924-2014), " ce point s'explique probablement par l'identification, à l'époque, des tigres aux léopards ${ }^{26}$ ". L'Insecte divin est donc ainsi placé dans le même camp que les « démons-tigres " mentionnés dans le texte introductif, et dans ce cas, il est possible d'interpréter cette scène de la version Masuda comme une composition dans laquelle les membres d'un même camp s'éliminent les uns les autres.

\section{Shōki (fig. 4)}

Selon Kobayashi, Shōki (ch. Zhong Kui) apparaît dans une anecdote recueillie dans l'Histoire non officielle des Tang (ch. Tang-yishi 唐逸史) de Lu Zhao 盧肇 (818-882). L'histoire raconte en effet que l'empereur Tang Xuanzong 唐玄宗 $(685-762 ;$ r. 712-756) vit un jour en rêve un démon maléfique capturé par un autre grand démon portant la tenue de cérémonie des fonctionnaires (coiffe, tunique bleue, ceinture traditionnelle et chaussures de cour). Après avoir éliminé son adversaire en lui arrachant les yeux et en le dévorant, ce dernier se 


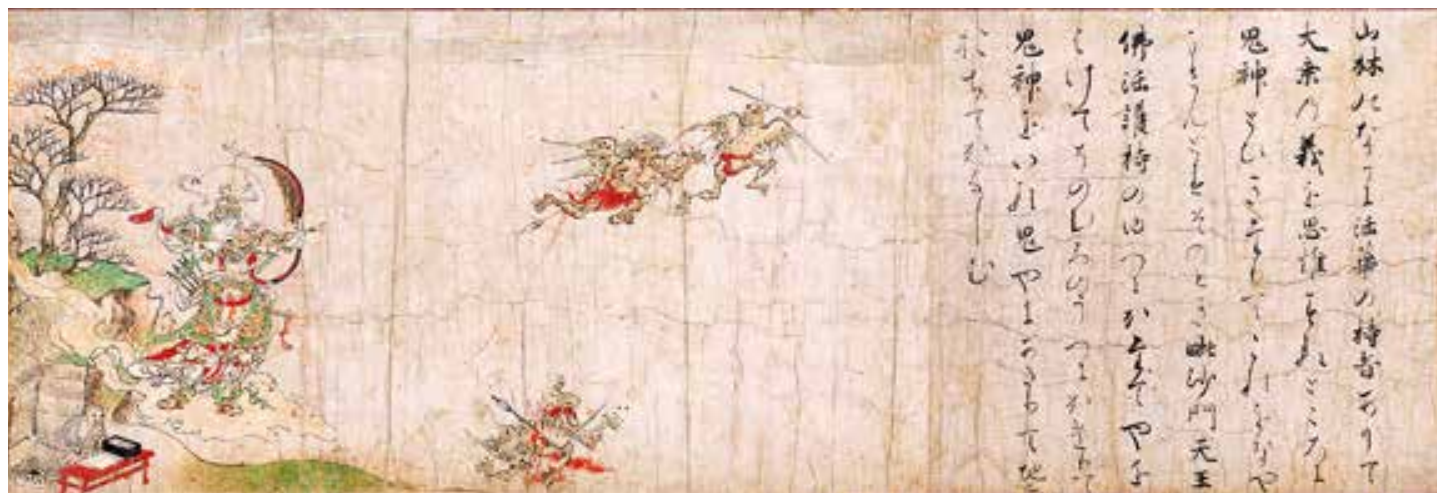

présenta à l'empereur : « Votre serviteur est Zhong Kui des monts Zhongnan, lauréat du concours des examens impériaux. " À son réveil, Xuanzong fit peindre son effigie par le célèbre peintre Wu Daoxuan 冥道玄 (680740), qu'il utilisa comme amulette de protection contre 5. Bishamonten 毘沙門天 (skt. Vaiśravana), Second Rouleau des Peintures des enfers (Masuda-ke-bon jigoku-zōshi otsukan 益田家本地獄草紙乙巻), fin du XII siècle, couleurs sur papier, Nara, Musée national de Nara, inv. 1106-5. les démons. Cette anecdote atteste de la croyance dans le rôle de Zhong Kui comme chef des esprits maléfiques.

Shōki occupé à l'élimination d'un démon de la pestilence en lui arrachant les yeux, tel qu'il est dépeint dans le rouleau japonais, apparaît donc dans un récit compilé dans l'Histoire non officielle des Tang. Cette anecdote est de plus confirmée par des documents datant du règne de Xuanzong qui mentionnent l'usage de portraits de Zhong Kui comme talismans, et l'on sait que c'est durant la dynastie Tang que $\mathrm{s}^{\prime}$ est fixée son iconographie ${ }^{27}$. En d'autres termes, le texte introductif de cette section de la version Masuda recoupe entièrement la légende de Zhong Kui telle qu'elle existait en Chine :

Dans le Jambudvīpa, il y a un être nommé Shōki. Il capture de nombreux démons de la pestilence, leur arrache les yeux, les démembre et jette le tout. Pour cette raison, les gens peignent et affichent cette scène sur leur porte afin de préserver la maisonnée de tout mal au début de l'année.

Une même fidélité aux sources chinoises s'observe dans la peinture qui le représente exactement tel qu'il est apparu en rêve à l'empereur Xuanzong, avec sa coiffe, sa tunique bleue, la ceinture traditionnelle et des chaussures de cour, occupé à arracher les yeux d'un petit démon.

\section{Bishamonten (fig. 5)}

Le texte introductif de la section de peinture raconte l'histoire suivante :

Dans les montagnes se trouvait un pratiquant du Sūtra du Lotus. Alors qu'il méditait sur la signification du grand véhicule, des esprits démoniaques surgirent, s'apprêtant à lui faire du mal. À ce moment, Bishamonten, le protecteur de la loi bouddhique, encocha d'une main une flèche sur son arc, monta sur le toit de la hutte du pratiquant et tira sur les démons. Ces derniers, atteints par ses flèches, tombèrent au sol dans de terribles douleurs.

La source de l'histoire qui fait de Bishamonten le protecteur des pratiquants du Sütra $d u$ Lotus se trouve dans le chapitre XXVI du même sūtra, intitulé " Les formules détentrices " (Darani-hon 陀羅尼品). Cependant, ce dernier ne va pas jusqu'au même niveau de détail et 
6. Bishamonten 毘沙門天 (skt. Vaiśravaṇa), détail, fin du XII ${ }^{\mathrm{e}}$ - début du XIII ${ }^{\mathrm{e}}$ siècle, encre, couleurs, or et argent sur panneau de soie, inv. 05.202. Boston, Museum of Fine Arts,

n'évoque pas une extermination des démons avec les flèches. Umezawa relève malgré tout des similarités entre Bishamonten et Kubera Yakșa, une divinité de la mythologie indienne qui commande aux âmes maléfiques demeurant dans le monde des ténèbres. Kubera Yakșa a été intégré dans le bouddhisme sous le nom de Kumbhīra (jp. Kubira 宮比羅), l'un des douze généraux célestes serviteurs du Bouddha Yakushi 薬師, puis a fini par fusionner avec la figure de Bishamonten.

Bishamonten étant considéré comme ne faisant qu'un avec Tamonten 多聞天, l'un des Quatre Rois célestes protecteurs de la loi bouddhique, son iconographie habituelle lui attribue, à l'instar de ce dernier, une pagode et une arme (hallebarde ou bâton). De son côté, Umezawa cite une peinture du British Museum figurant Bishamonten et sa cour faisant une tournée d'inspection du monde ${ }^{28}$ comme exemple iconographique des régions de l'Ouest, d'où provient précisément la croyance dans la divinité Kubera Yakșa. Bien qu'il s'agisse d'une figuration à caractère général dans laquelle Bishamonten a pour attributs une pagode et une hallebarde, l'un de ses serviteurs est représenté, une flèche encochée sur son arc, sur le point d'abattre un esprit maléfique ailé qui vole dans un ciel vide.

$\mathrm{Au}$ Japon même, on trouve également des représentations de Bishamonten relevant de cette tradition iconographique, comme dans une œuvre exécutée dans l'archipel à la fin de l'époque de Heian ou au début de l'époque de Kamakura et transmise par le monastère Enryaku-ji du mont Hiei $^{29}$, aujourd'hui conservée au Boston Museum of Fine Arts (fig. 6). Ses troupes sont notamment composées de cinq sortes d'esprits démoniaques munis d'armes diverses, et l'un d'entre eux est effectivement dépeint un arc à la main. Dans son étude sur la version Masuda, Miyajima Shin'ichi suggère lui aussi que le regroupement de Bishamonten et de ses serviteurs en une seule peinture en lien dans cette tradition iconographique a eu comme conséquence la fusion des motifs et la création de la figure du Bishamonten archer que l'on retrouve ici ${ }^{30}$.

Ainsi, le Bishamonten de la version Masuda présente lui aussi un double aspect, étant à la fois meneur d'esprits démoniaques, et divinité bienfaisante et protectrice de l'ordre du monde.

\section{Le démon chassé (fig. 7)}

Le musée d'art de la ville de Fukuoka possède une peinture du Démon chassé qui a pour thème un démon banni par Bishamonten et poursuivi par d'autres créatures autrefois dans le même camp que lui. Ici aussi, l'image met en scène un conflit entre des esprits maléfiques semblables. Miyajima Shin'ichi signale qu'une anecdote en lien avec cette scène est recueillie dans un ouvrage à tonalité bouddhique, sans doute compilé au Xve siècle, les Essais à l'aube d'une bécasse dans son nid (Tōden-gyōhitsu 榻鴫暁筆, chapitre XXXII : « Le démon qui enfreint la loi bouddhique ", Hanpōki 犯法鬼) ${ }^{31}$. Miyajima a identifié la source de cette histoire dans le Recueil d'apologues divers (ch. Zapiyu-jing 雜譬喻經) ${ }^{32}$, ainsi que dans le Recueil d'apologues divers extraits de la multitude des livres saints (ch. Zhongjing zhuan zapiyu 眾經撰雜譬喻) dans la traduction de Kumārajīva (344-413) ${ }^{33}$. Voici les grandes lignes du récit retranscrit dans le Recueil d'apologues divers. Un moine bouddhiste, qui avait perdu les offrandes de ses fidèles contrairement à son devoir, marchait sur un chemin en pleurant. Ce faisant, il tomba sur un démon, lui aussi banni par Bishamonten pour avoir tourné le dos à la loi bouddhique. Le démon, invisible aux yeux des profanes ${ }^{34}$, fit monter le moine sur son épaule gauche et se mit en route. C'est alors que les gens, voyant ce moine voler dans le ciel, le vénérèrent comme un grand saint et le rappelèrent dans le temple où ils lui firent maintes offrandes. Le moine partagea les dons avec le démon, mais un jour, 


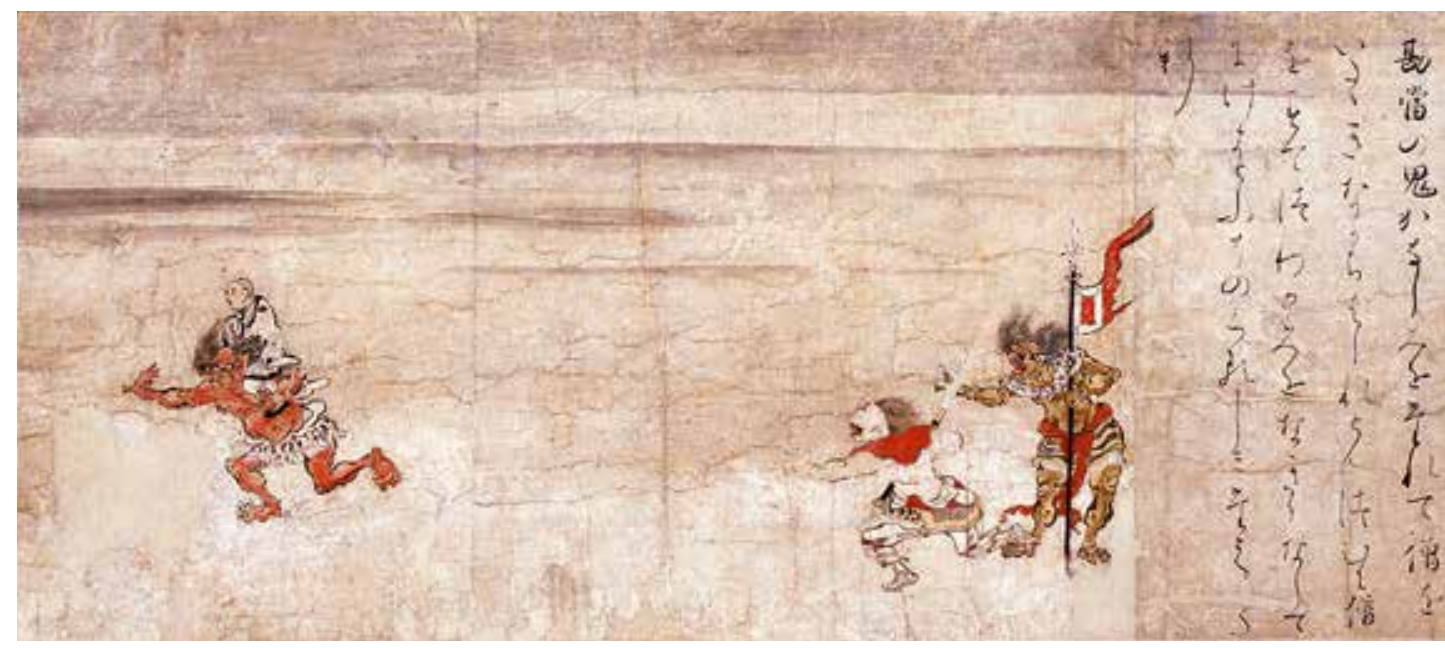

7. Le Démon chassé (Kandō no oni 勘当の鬼), fin du XII ${ }^{\mathrm{e}}$ siècle, Fukuoka, musée d'Art de la ville, inv. 6-B-12. ils furent découverts par des serviteurs de Bishamonten. À ce moment, le démon prit la fuite en jetant le moine qui tomba, se brisa le cou et mourut.

Il manque une partie du texte introductif dans la peinture du musée d'Art de la ville de Fukuoka, mais il a, semble-t-il, existé une copie de ce texte, réalisée par

le peintre Tanaka Shinbi 田中親美 (1875-1975). Bien que sa localisation actuelle soit inconnue - ce qui rend difficile les vérifications -, Fukui Rikichirō en a autrefois transcrit le texte intégral et publié le facsimile ${ }^{35}$. C'est sur la base de ce facsimile qu'il est possible de confirmer que les dix-huit premières colonnes du texte sont perdues dans la version de Fukuoka, qui correspond à la partie soulignée dans la traduction ${ }^{36}$ :

Il y avait un démon au service de Bishamonten. Son cœur était plein de mauvaises pensées, et il ne répondait pas à la volonté de son maître. Exilé par ce dernier,

il fut chassé aussitôt du Palais de Cristal $^{37}$ et descendit dans le monde d'en bas. Alors qu'il s'apprêtait à y résider, il rencontra sur la route un moine chassé de son monastère en Inde, qui errait de-ci de-là. Ils s'interrogèrent mutuellement sur la raison de leur sort, puis le démon le fit monter sur son épaule et reprit sa marche. Comme le démon cachait son corps avec des formules magiques, il ne pouvait être vu par des yeux profanes. Ainsi, les gens avaient l'impression que le moine volait dans les airs. Vénérant ce miracle, ils lui firent des offrandes. Le moine, ayant reçu ces offrandes, les partagea avec le démon pour les manger. Comme ils vivaient ainsi tous les deux, ils rencontrèrent deux démons Yasha du Palais de Cristal descendus dans ce bas monde et marchant sur le chemin. À leur vue, les Yasha, se disant: "Voilà l'idiot exilé par Bishamonten!", se mirent à le poursuivre pour l'attraper. Le démon exilé, laissant couler des larmes de tristesse, prit le moine dans ses bras et s'enfuit avec lui en courant, mais il finit par l'abandonner. Il erra en courant jusqu'à se perdre lui-même. Il est difficile de supporter une telle souffrance.

Bien que le contenu de ce texte d'introduction recoupe le sens général du Recueil d'apologues divers, les deux dernières phrases du texte ne se trouvent non seulement pas dans la source chinoise, mais présentent de plus un point de vue particulier commun avec les textes introductifs des sections Sendan Kendatsuba et Bishamonten de la version Masuda, ce qui confirme qu'elles formaient à l'origine un unique rouleau.

La peinture représente un démon portant un moine sur son épaule, et poursuivi par deux autres démons brandissant une lance et un râteau. Son lien sur le plan thématique 
est étroit avec la section Bishamonten de la version Masuda. De plus, les attributs des deux démons, la lance et le râteau, sont ceux des cinq grands yasha qui sont également figurés dans la représentation de Bishamonten longtemps conservée dans le trésor du mont Hiei et que nous avons déjà mentionnée (Boston Museum of Fine Arts). De là, il est possible de reconstituer un lien entre le Démon chassé et l'iconographie du bouddhisme Tendai. Ce point est également suggéré dans la section Bishamonten ${ }^{38}$.

\section{La version Masuda comme Rouleau des esprits démoniaques}

Les différents points abordés ci-dessus et un nouvel examen de ces peintures permettent de suggérer à nouveau qu'elles ne comportent pas de différence dans la représentation des démons maléfiques et des divinités bienfaisantes. Ces dernières y sont même plutôt figurées comme des êtres surpassant en étrangeté leurs adversaires. L'iconographie inhabituelle de Bishamonten comme " archer " en fait le chef des esprits démoniaques. Or, dans le Démon chassé, un serviteur maléfique du même Bishamonten se voit poursuivi par ses anciens compagnons. En conséquence, ne pourrait-on pas comprendre ces six sections de peinture comme des scènes nous montrant des esprits maléfiques de nature semblable aux prises à des combats mortels, ces derniers ayant une nature ambivalente à la fois bonne et mauvaise ? Si c'est bien le cas, nous pourrions alors, en nous inspirant de dénominations telles que Rouleau des enfers ou Rouleau des esprits faméliques, renommer ces six sections Rouleau des esprits démoniaques.

Ce faisant, nous serions en mesure de proposer une nouvelle interprétation considérant ces six sections comprises jusqu'à présent uniquement en tant $\mathrm{qu}^{\prime}$ " élimination des démons maléfiques par les bonnes divinités " comme le " monde des démons " intégré dans une partie du monde des cycles de transmigration des âmes. En d'autres termes, à travers le système des cycles de réincarnation dépeints dans le Rouleau des enfers, le Rouleau des esprits faméliques et les six sections du Rouleau des esprits démoniaques nouvellement mentionné ici, il deviendrait possible de clarifier davantage la vision bouddhique du monde partagée dans le Japon pendant la période de gouvernement retiré.

\section{Des titans omniprésents}

L'interprétation de ces six sections de peinture comme dépeignant la «Voie des esprits démoniaques " nous permet d'aborder maintenant le problème de la proximité de nature entre ces esprits et les titans. En effet, la conception du cycle de transmigration en Cinq Voies (enfers, animaux, esprits démoniaques, êtres humains et êtres célestes) n'infère pas que la Voie des titans n'existe pas. Disons plutôt que cette dernière se trouve répartie de façon omniprésente dans les autres Voies, du fait que les titans sont dotés d'un caractère ambigu. Le corpus canonique du bouddhisme inclut de fait les titans dans plusieurs d'entre elles : êtres célestes, animaux et esprits démoniaques ${ }^{39}$. Par exemple, le Sūtra de la lumière dorée (Konkōmyō-kyō 金光明経) traduit par Dharmakṣema classe les huit catégories de déités - dont les titans et les musiciens célestes -, ainsi que les rois-dragons, dans la catégorie des esprits démoniaques, et les considère tous comme des divinités protectrices de la loi bouddhique ${ }^{40}$. De plus, dans L'Aide-mémoire de la Vraie Loi (Shōbōnenjo-kyō 正法念処経), qui sert également de source au Rouleau des enfers et au Rouleau des esprits faméliques, les titans sont présents dans deux Voies, celle des esprits faméliques précisément, et celle des animaux, et sont décrits comme partie prenante de chacune d'entre elles ${ }^{41}$. 
Enfin, le Commentaire sur la Grande Perfection de Sagesse (Daichido-ron 大智度論) de Nāgārjuna (150-250) va jusqu'à discuter de façon précise l'ambiguïté dans la définition de ces titans. Ce commentaire, qui compile l'ensemble des gloses du Sūtra du Cour de l'Infinie Sagesse (Maka-hannya-haramitsu-kyō 摩訶般若波羅蜜経), fournit des explications détaillées à propos du cycle des Six Voies de transmigration. Ces dernières furent traduites en chinois par Kumārajīva et importées jusqu'au Japon avant le vIII ${ }^{\mathrm{e}}$ siècle. Dans le volume XXX de ce traité, les titans sont classés dans une vaste catégorie comprenant également les chantres (skt. kimnara) et les musiciens célestes (skt. gandharva), ainsi que les serviteurs de Virūụhaka, roi-gardien céleste du Sud (Zōjōten 増長天) : gnomes (skt. kumbhānda), ogres (skt. yakșa), goules (skt. rākșasa) ou encore démons puants (skt. bhüta) ${ }^{42}$. Au sein de cette catégorie hétérogène, les titans, les chantres, les musiciens célestes et les gnomes sont des divinités bienfaisantes, et incluses à ce titre dans les huit catégories de déités protectrices de la loi bouddhique. En revanche, les ogres, les goules et les démons puants sont assimilés aux esprits maléfiques faisant obstruction à la loi bouddhique. Outre ses développements sur le bien et le mal, le texte comporte également le passage suivant ${ }^{43}$ :

Quelqu'un dit : "Selon une certaine conception, il y a onze classes d'êtres dans le monde des désirs (skt. kāmaloka). Autrefois, on parlait des Cinq Voies, mais maintenant on ajoute les titans." On lui demande : "Admettons que l'on intègre les titans dans les Cinq Voies, ils ne sont ni des êtres humains, ni des êtres célestes; ils ne sont ni des êtres des enfers aux nombreuses souffrances, ni des animaux aux formes étranges. Conviendrait-il donc de les intégrer dans la Voie des démons ?" Il répond : “Non. La force des titans est comparable à celle des divinités des trente-trois cieux. Pour quelle raison ? Parce qu'ils sont parfois vaincus par les diverses divinités, mais qu'ils peuvent parfois les battre également. Il est mentionné dans un sūtra que Taishakuten 帝釈天 (skt. Śakra) fut un jour battu par les titans. Les quatre forces militaires (les éléphants, la cavalerie, les fantassins et les chars) pénétrèrent à l'intérieur des trous d'une racine de lotus pour se cacher dans l'ombre. Ils reçurent la joie des cinq plaisirs, comme les êtres célestes, et devinrent des disciples de Bouddha. Comment des titans aussi puissants pourraient-ils être assimilés à des esprits faméliques ? En conséquence de quoi il devrait bien y avoir Six Voies."

L'argumentation suivante se cristallise sur la question de la nature des titans, et s'interroge sur la conception cosmologique du monde, qu'il faut concevoir soit en Six Voies (titans inclus), soit en Cinq (dont une réunirait titans et démons). La citation ci-dessus se conclut néanmoins sur l'impossibilité d'assimiler les titans aux esprits faméliques, étant donné qu'ils sont de taille à rivaliser avec les êtres célestes et qu'ils peuvent également devenir les disciples de Bouddha. Cependant, dans le volume X de ce même Commentaire sur la Grande Perfection de Sagesse, la théorie de Kātyāyani-putra, l'un des dix grands disciples de Sākyamuni, fait également allusion à la théorie des Cinq Voies intégrant les titans dans la Voie des esprits démoniaques ${ }^{44}$. Autrement dit, un même sūtra peut ainsi faire figurer côte à côte des problématiques et des théories variées, voire contradictoires au sujet de la nature réelle des titans.

Ces derniers possèdent donc un double aspect ontologique fondamental (le bien et le mal), ce qui leur vaut d'être également considérés comme des esprits démoniaques. Cette observation constitue aussi le point de départ de l'argumentation que l'on trouve dans le Commentaire sur la Grande Perfection de Sagesse. Un réexamen de la version Masuda et du Démon chassé sur la base de cette constatation permet de dégager une nouvelle signification des combats que se livrent dieux bienfaisants et esprits maléfiques, et de la victoire des uns sur les autres : ces peintures ne pourraient-elles pas aussi figurer les combats entre entités démoniaques, et donc représenter la Voie des titans? 
Cette hypothèse va contre les précédentes études qui n'ont pas identifié la Voie des titans comme thème principal de ces six peintures, car l'iconographe des titans relevant des peintures des Six Voies à partir de l'époque de Kamakura est très différente. Cependant, le recours aux textes du canon bouddhique - qui considèrent titans et esprits démoniaques comme une seule et même Voie - permet d'interpréter la version Masuda et le Démon chassé à la fois comme une illustration de la Voie des esprits démoniaques, et comme une représentation de celle des titans.

\section{Les titans au combat}

Si l'on tient ces six sections de peinture pour des figurations de titans, il faut alors s'interroger à nouveau sur la raison pour laquelle cette iconographie n'est pas du tout reprise dans les nombreuses figurations des Six Voies réalisées à partir de Kamakura. Le XIII ${ }^{\mathrm{e}}$ siècle voit une forte augmentation du nombre de peintures (rouleaux horizontaux et rouleaux verticaux) comportant des illustrations des Six Voies : par exemple, la version de l'ère Jōkyū (1219-1222) du Rouleau sur l'origine miraculeuse du sanctuaire de Kitano Tenjin (Kitano Tenjin engi emaki 北野天神縁起絵巻) du sanctuaire Kitano Tenman-gū, les Peintures des Six Voies (Rokudō-e 六道絵) du temple Shōjuraigō-ji 聖衆来迎寺 et du temple Gokuraku-ji 極楽寺， ou bien encore la Peinture des dix mondes (Jikkai-zu 十界図) du temple Zenrin-ji 禅林寺. Tous ces témoignages offrent des représentations de titans aux prises avec Taishakuten et vaincus par ce dernier. La structure iconographique fondamentale de ce genre est fournie par le Compendium pour la renaissance en Terre pure rédigé en 985 par le moine Genshin de l'école Tendai 天台. Cet ouvrage est constitué d'une compilation de citations tirées de différents sütra, et expose de façon simple et claire, en trois livres et dix chapitres, les points essentiels de la croyance permettant de garantir la renaissance en Terre pure. Intitulé « Détestation de ce monde impur " (Onri edo 厭離穢土), le chapitre premier décrit les Six Voies que sont les enfers, les esprits faméliques, les animaux, les titans, les êtres humains et les êtres célestes. C'est ce texte qui va servir de base pour la structuration des peintures des Six Voies au Moyen Âge sur un plan iconographique.

Il faut cependant noter que le Compendium pour la renaissance en Terre pure est peu disert sur la Voie des titans et qu'il ne fournit que les quelques éléments suivants ${ }^{45}$ :

\footnotetext{
Quatrièmement, on peut expliquer que la Voie des titans se divise en deux.

Les titans supérieurs résident au fond de l'immense océan au nord du mont Meru,

et les titans inférieurs se trouvent en plein cœur des montagnes au centre

des quatre grands continents. Lorsque le tonnerre gronde, les titans disent que

ce sont les tambours des êtres célestes. Ils sont alors terrorisés, s'affolent

et sombrent dans l'abattement. De plus, ils sont sans cesse attaqués par les êtres

célestes : tantôt ils les mettent en pièces, tantôt ils perdent la vie. Il est également

dit que, d'elles mêmes, des armes s'en prennent à eux trois fois par jour.

Leur affliction et leur souffrance sont telles qu'on ne peut la décrire tout entière.
}

En comparaison des longues descriptions consacrées aux enfers ou aux esprits faméliques, largement étayées par différents sūtra, on peut inférer de la brièveté de ces propos que non seulement Genshin ne s'intéressait pas tellement à cette Voie, mais qu'en plus, à l'époque de rédaction de ce texte au Japon (le milieu de l'époque de Heian), la compréhension des titans y était encore balbutiante.

Le registre supérieur du rouleau suspendu figurant la Voie des titans et conservé au temple Shōjuraigō-ji (fig. 8) présente un commentaire presque entièrement tiré du Compendium pour la renaissance en Terre pure, ce qui permet d'identifier clairement le traité de Genshin comme la source de la peinture ${ }^{46}$. Il n'est cependant pas possible 


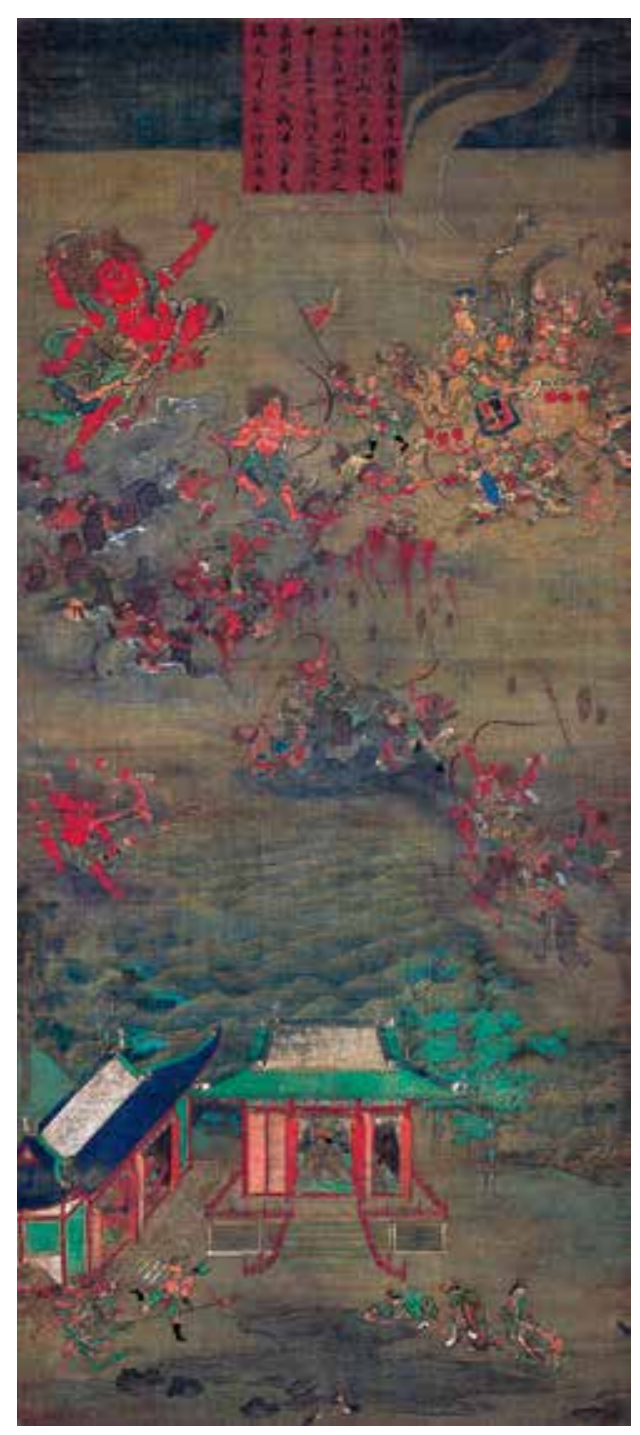

8. La Voie des titans 阿修羅道 (skt. asura), XIII siècle, couleurs sur soie, Shiga, temple Shōjuraigō-ji. d'expliquer tous les motifs de l'image en se contentant de la description sommaire mentionnée ci-dessus. En revanche, un recoupement de ces motifs avec les livres XVIII à XXI de L'Aide-mémoire de la Vraie Loi, sur lequel s'appuie le compendium de Genshin, permet de confirmer leur correspondance avec les quatre rois des titans évoqués en détail à la fin du " Chapitre sur les animaux" (Chikushō-bon 畜生品).

La figure située au centre de la peinture est le roi des titans Rago qui cache le soleil de sa main gauche. Il est décrit dans L'Aide-mémoire de la Vraie Loi comme un titan au corps gigantesque qui de temps à autre occulte le soleil et la lune avec ses mains, ce qui permet d'expliquer l'origine des éclipses de soleil et de lune. Devant lui se trouve le roi des titans Hakasha, décrit dans L'Aide-mémoire... comme le plus belliqueux de tous. Dans le registre supérieur, Taishakuten, monté sur un éléphant blanc, fait face à ce dernier. Ce même texte explique que si les hommes accumulent les bonnes actions en grand nombre dans leur vie présente, les troupes de Taishakuten remporteront la victoire, mais que, dans le cas contraire, les titans triompheront de leurs adversaires. La figure de Taishakuten coiffé d'un diadème, revêtu d'une armure et d'un casque somptueux, et tenant une épée dans sa main droite, symbolise la divinité protectrice de la loi bouddhique. L'assaillant de Taishakuten depuis le registre inférieur, armé d'un arc et d'un foudre à trois pointes (skt. vajra), est le roi des titans Keman. Selon L'Aide-mémoire de la Vraie Loi, il réside dans le troisième niveau du monde des titans et provoquerait l'apparition des comètes. Flèches et rochers pleuvent sur l'armée des titans, tels un déluge de grêle. Ce point correspond tout à fait aux armes qui les attaquent trois fois par jour selon le Compendium pour la renaissance en Terre pure. La représentation, à l'arrière-plan, d'un océan s'étendant à perte de vue permet d'évoquer le monde des titans, qui demeurent au plus profond des océans. Le registre inférieur de l'image montre un palais et l' "étang où l'on voit tout " (issaikan-chi

一切観池), où se reflètent le monde d'ici-bas et tout ce qui s'y passe. Dans le bâtiment à étages à gauche de l'image, on peut voir un roi des titans de retour dans son palais après avoir pris la fuite, vraisemblablement le roi Yūken, qui demeure dans le deuxième niveau du monde des titans. En effet, L'Aide-mémoire de la Vraie Loi explique que son palais se trouve dans l' «étang où l'on voit tout ". Enfin, une dame coiffée d'un diadème, sans doute l'épouse du roi des titans, est figurée en larmes, effondrée sur le sol du palais au centre de ce registre. Selon L'Aide-mémoire..., les guerriers vaincus de l'armée des titans ayant fait croire à leurs épouses que leur parti est victorieux, ces dernières découvrent dans l' « étang où l'on voit tout " la réalité de la tragédie et versent des larmes d'affliction. 
Dans cet ensemble, outre leurs chefs, les forces armées respectives des rois des titans et de Taishakuten sont très nombreuses. Mais, si les guerriers de Taishakuten sont revêtus d'armures somptueuses et chevauchent des nuages blancs, l'armée des titans, constituée d'êtres difformes se démenant dans des nuages noirs, est représentée de façon nettement défavorable. Notons en outre qu'au centre de l'image, le tonnerre effrayant les titans selon le Compendium pour la renaissance en Terre pure est figuré sous la forme de Raijin 雷神, le dieu du tonnerre, et que la souffrance des titans, sans cesse attaqués par des êtres venus d'un autre monde, est dépeinte avec un soin tout particulier.

En conférant un rôle de premier plan aux titans qui combattent l'armée de Taishakuten, la peinture du Shōjuraigō-ji fait état d'une conception précise de cette Voie. L'opposition est claire entre Taishakuten, considéré comme une divinité bienfaisante, et les titans, tenus pour des esprits maléfiques et à ce titre perpétuellement persécutés. Cette peinture est également particulière en ce qu'elle propose une frontière extrêmement nette entre le bien et le mal, et atteste une conception profondément enracinée dans la pensée propre au bouddhisme de la Terre pure (Jödo 浄土), qui garantit « à ceux qui accumulent les bonnes actions la renaissance en paradis et aux méchants la chute au fond des enfers ».

La Voie des titans dépeinte dans le rouleau du temple Shōjuraigō-ji - qui date, rappelons-le, du XIII ${ }^{\mathrm{e}}$ siècle - fait également écho à la structure de peintures de la fin de l'époque de Heian (XII ${ }^{\mathrm{e}}$ siècle) telles que la version Masuda et le Démon chassé, en ce sens que ces dernières présentent semblablement des combats opposant les titans et Taishakuten, c'est-à-dire des êtres de nature semblable et transcendant les simples mortels. Cependant, on peut déceler une évolution rapide dans l'iconographie des Six Voies dès le début de la période de Kamakura, les titans étant désormais dépeints comme les éternels vaincus de combats sans fin.

\section{Récits guerriers et titans}

Le Japon médiéval voit en effet se multiplier les peintures de titans souffrant dans des combats. Nous allons maintenant chercher à comprendre la raison de leur intégration au genre des peintures des Six Voies, en partant du corpus littéraire de l'époque. Dans le deuxième livre du Recueil des trésors (Hōbutsu-shū 宝物集) ${ }^{47}$, on retrouve une description du cycle de transmigration, manifestement basée sur le Compendium pour la renaissance en Terre pure ${ }^{48}$ :

Les titans étant plein de rage, il n'y a rien qui puisse calmer leur cour furieux.

Et ce n'est pas tout : ils ont des accès d'abattement trois fois par jour. Ils se lamentent

quand les tambours du ciel se mettent à résonner d'eux-mêmes.

Les cris des multitudes souffrant dans les enfers,

la voix de ceux plongés dans ces angoisses variées,

la voix des démons affamés qui, poussés par la faim et la soif,

recherchent à boire et à manger,

les grandes voix sonores émises

Par les titans et leurs semblables,

Résidant au rivage de l'Océan

Lorsqu'ils parlent entre eux ;

c'est ainsi que celui qui prêche la Loi,

résidant sereinement ici même,

entendra la multitude des voix venant de $\operatorname{loin}^{49} \ldots$

Selon ce qui est dit ici, les titans demeurent en permanence au fond de l'océan. Cependant, comme ils font aussi retraite dans les cieux ${ }^{50}$, il n'est pas besoin d'en parler en détail ici. Ce qui concerne les cieux sera abordé ailleurs. 
Beaucoup de poèmes furent composés sur le thème de l'amertume.

Le moine Kaishū 戒秀法師 (?-1015)

J'ai ramassé

- que l'amertume est amère -

des algues marines

et la fumée s'en va

dans une direction inattendue ${ }^{51}$

Minamoto no Tameyoshi 源為善 (970? -1042)

Le brame des daims

qui se couchent à l'automne

enroulés dans les lespédèzes,

en tout premier je l'ai entendu

tout à mon amertume ${ }^{52}$

Le ministre de droite de Horikawa [Fujiwara no Yorimune 藤原頼宗 (993-1065)]

Je reste ignoré d'elle

- que l'amertume est amère -,

ce vêtement

teinté de mauve

le retournerai-je $\mathrm{j}^{53}$ ?

Le Prince San no Miya [autre nom de Minamoto no Arihito 源有仁 (1103-1147),

surnommé ministre de gauche de Hanazono]

Fleur d'acore,

quelle amertume !

tu ne m'as pas rendu visite...

Alors qu'en ce jour j'aurais

voulu te plaire !

Le moine Shakua 釈阿 [nom religieux de Fujiwara no Shunzei 藤原俊成 (1114-1204)]

Puisque j'ai renoncé

à mes amours vaines,

resplendissant de fleurs automnales

le paysage de la lande

me sera bien amer

Cette source reprend telles quelles les explications du Compendium pour la renaissance en Terre pure concernant les titans. De plus, elle considère que les titans font partie de la Voie des êtres célestes ( Cependant, comme ils font aussi retraite dans les cieux, il n'est pas besoin d'en parler en détail ici »), et se contente de ce raccourci, sans fournir d'explications précises à leur sujet. En outre, les waka 和歌 ${ }^{54}$ cités à la suite de ces propos comme des illustrations de la Voie des titans, décrite comme " amère " (netashi), chantent la souffrance et le péché de l'amertume (netaki koto), mais de façon détournée et sans mentionner les souffrances des " combats ". Or, l'époque de rédaction du Recueil des trésors correspond à peu près à celle de la version Masuda et du Démon chassé, ce qui permet donc de suggérer la façon dont était comprise la Voie des titans à la fin de l'époque de Heian.

De plus, on peut observer à cette même époque une augmentation du corpus de waka et de kanshi 漢詩 $^{55}$ ayant pour thème les titans au combat, emboîtant ainsi le pas au Recueil des trésors. Pour prendre l'exemple d'un poème en langue vernaculaire, le Recueil de l'ermitage (Sanka-shū 山家集) ${ }^{56}$ propose des poèmes sur le thème des Six Voies, à raison d'un poème par Voie, et précédés du texte introductif suivant :

Alors que je composais des poèmes sur les Six Voies. L'un d'entre eux, consacré aux titans, chante leur fureur à combattre :

Qu'il est vain 
le cour des titans

qui ne songe qu'à batailler

et ne forme en son sein

que les germes de la colère!

En outre, il convient de noter que, dans les récits guerriers composés pendant les époques de Kamakura et des cours du Nord et du Sud (1333-1392), la Voie des titans apparaît très fréquemment comme une expression rhétorique de la guerre ${ }^{57}$. En voici quelques exemples suggestifs : le Dit des Heike (Heike monogatari 平家物語), "Le livre des aspersions " (Kanjō no maki 潅頂巻 $)^{58}$; les Chroniques de la grandeur et de la décadence des Taira et des Minamoto (Genpei jōsui-ki 源平盛衰記), livre XV ${ }^{59}$; les Chroniques des troubles de l'ère Shōkyū (Shōkyū-ki 承久記), livre $\mathrm{II}^{60}$; le Dit des Soga (Soga monogatari 曽我物語), livre $\mathrm{V}^{61}$; la Chronique de la grande paix (Taiheiki 太平記), livre $\mathrm{X}^{62}$. Dans les récits guerriers de l'époque de Kamakura, le recours fréquent à la métaphore des titans combattants devient, on le voit, un topos récurrent de la description des batailles. La représentation de la Voie des titans observée dans le rouleau du Shōjuraigō-ji peut donc s'expliquer, non seulement par ses sources directes (le Compendium pour la renaissance en Terre pure et L'Aide-mémoire de la Vraie Loi), mais aussi comme une peinture qui reflète d'une façon particulièrement intense le monde des récits guerriers nés précisément à cette époque troublée.

La version Masuda et le Démon chassé ont été élaborés à la fin de la période de Heian. L'identification de ces sections de rouleau comme des illustrations de la "Voie des esprits démoniaques " et, par analogie, de la Voie des titans, ne laisse pas de surprendre si l'on tient compte de leur décalage formel avec la "Voie des titans " telle qu'elle est représentée dans les peintures des Six Voies de la période de Kamakura. Mais la souffrance engendrée par les combats opposant des esprits démoniaques, possédant tous une même nature ambivalente, se situe précisément au fondement de la conception de cette Voie suggérée par les représentations des Six Voies de la période de Heian. On peut donc se demander si elle n'est pas révélatrice de la façon dont l'entourage proche de l'empereur retiré Go-Shirakawa lui-même les comprenait.

Le groupe d'œuvres comprenant le Rouleau des enfers, le Rouleau des esprits faméliques, le Rouleau des maladies - auxquelles j'ajoute les six sections de peinture qu'il conviendrait d'appeler le Rouleau des esprits démoniaques -, exprime non seulement la terreur de vivre dans ce monde de l'errance qui est celui des transmigrations, mais également une compassion, et même parfois une certaine curiosité, envers les êtres souffrants. En particulier dans les six peintures étudiées dans cet article et dans les six sections conservées de L'Enfer des mauvais moines (Shamon jigoku 沙門地獄), un inexplicable sentiment vis-à-vis des êtres ambigus que sont les esprits démoniaques permet aux images et à leurs textes introductifs d'échapper à une opposition par trop manichéenne entre le bien et le mal. S'ils sont redoutables, les esprits démoniaques doivent également susciter la compassion. S'ils s'attaquent aux êtres humains, ils peuvent aussi être secourables et les protéger. Cet ensemble d'œuvres consacrées aux Six Voies permet donc de suggérer une forme de symbiose entre ces esprits maléfiques et les êtres humains, mais également une vision empathique considérant l'ensemble des êtres du cycle de transmigration comme relevant d'une nature foncièrement commune.

Cette contribution a été traduite du japonais par François-Karl Gschwend. 


\section{Yamamoto Satomi}

Professeure au département de Lettres, Arts et Sciences de Waseda University (Ph.D. Waseda University, 2007), Yamamoto Satomi étudie et enseigne particulièrement l'histoire de la peinture médiévale japonaise, en particulier celle de la peinture bouddhique narrative. Elle a reçu le Prix du ministère de l'Éducation pour les beaux-arts en 2016 (66 édition), pour son ouvrage 九相図 をよむ Kyusōzu wo yomu (Tōkyō, Kadokawa, 2015). Elle vient de publier Chōsei Bukkyō kaiga no zuzōshi 中世仏教絵画の図像誌 A Genealogy of Imagery in Medieval Buddhist Paintings: From Six Realms of Rebirth to Nine Stages of Decay (Tōkyō, Yoshikawakōbunkan, 2020).

\section{NOTES}

1. Cela peut sembler contradictoire, mais malgré leur aspect courroucé et agressif, ces divinités ont un rôle positif en ayant la charge de protéger le bouddhisme et ses pratiquants, $\mathrm{NdT}$.

2. Masuda Takashi 益田孝(1848-1938), collectionneur, avait accumulé un grand nombre de belles pièces d'art japonais entre la fin du XIX et le début du XX $X^{e}$ siècle. Comme ce rouleau faisait partie de ses pièces de collection, il est coutume de l'appeler " version Masuda » (jp. Masuda-ke-bon 益田家本).

3. Infra, la version Masuda. Pour les transcriptions, «jp. » désigne le japonais, « ch. » le chinois, et « skt. » le sanskrit. En l'absence de précision, le terme est japonais, $\mathrm{NdT}$.

4. Kobayashi Taichirō 小林太市郎, «Hekija emaki ni tsuite » 辟邪絵巻に就て [À propos du Rouleau des peintures talismaniques], dans Kokka 國華, n 621 , 622, 623, 625, 626, 628, 1944 ; étude rééditée dans Yamato-e shiron 大和絵史論 [Études sur l'histoire de la peinture japonaise], Tōkyō, Zenkoku shobō, 1956, ainsi que dans Kobayashi Taichirō chosaku-shū 小林 太市郎著作集 [CEuvres de Kobayashi Taichirō], vol. 5, Tōkyō, Tankōsha, 1974.

5. Fukui Rikichirō 福井利吉郎, "Chikushō-dō zanketsu to Sanrōjin no maki » 畜生道残欠と三老人巻 [Les fragments du Rouleau de la Voie des animaux et le Rouleau des trois vieillards], dans MUSEUM, n 109, 1960 ; étude rééditée dans Fukui Rikichirō bijutsushi ronshū 福井 利吉郎美術史論集 [Études en l'histoire de l'art de Fukui Rikichirō], Tōkyō, Chūōkōron bijutsu shuppan, 1999.

6. Miyajima Shin'ichi 宮島新一, «Hekija-e: wa ga kuni ni okeru juyō » 辟邪絵一わが国における受容一 [La réception au Japon des peintures talismaniques], dans Bijutsu kenkyū 美術研究 [The Journal of Art Studies], n 331, 1985 ; étude rééditée dans Kyūtei gadan-shi no kenkyū 宮廷画壇史の研究 [Recherches sur I'histoire du milieu artistique à la cour], Tōkyō, Shibundō, 1996.

7. Umezawa Megumi 梅沢恵, «Ya o hagu Bishamontenzō to hekija-e no shudai » 矢を矧ぐ毘沙門天像と「辟 邪絵」の主題 [Le Bishamonten archer et le thème des peintures talismaniques], dans Chūsei kaiga no matorikkusu II 中世絵画のマトリックス [Matrice des peintures médiévales II], Sano Midori 佐野みどり, Kasuya Makoto 加須屋誠 et Fujiwara Shigeo 藤原重雄 (éd.), Tōkyō, Seikansha, 2014.

8. Le petit véhicule correspond au bouddhisme le plus ancien et le plus proche de l'enseignement du Bouddha historique en Inde. Le qualificatif péjoratif de "petit » lui vient du grand véhicule, mouvement né des siècles plus tard en Chine, et qui fait du bouddhisme, non une religion du Salut réservée à une élite spirituelle, mais un moyen de progression destiné à sauver la totalité des êtres du monde, NdT.

9. Selon I'hindouisme, puis le bouddhisme, tous les êtres du monde relèvent, au cours de leur transmigration, d'une Voie (ou condition) dont la nature bonne ou mauvaise - dépend des actions commises dans les vies antérieures, selon le principe de la rétribution karmique. Ce cycle est décrit différemment selon les sources et les époques, les Voies les plus mauvaises étant les enfers, les animaux et les esprits faméliques (condamnés au tourment de la faim et de la soif), et les meilleures étant les êtres célestes et les êtres humains. La Voie des titans a un statut plus ambigu, d'où les traitements différenciés dont elle a fait l'objet, NdT.

10. Cet ouvrage fondamental du bouddhisme japonais présente les points essentiels permettant de renaître dans la «Terre pure » (c'est-à-dire le paradis) du Bouddha Amida, NdT.

11. Taishōzō vol. 1, 182a.

12. Taishōzō, vol. 24, 283 bc.

13. Taishōzō, vol. 23, 811c-1812a.

14. Ce recueil de contes étranges a été rédigé en Chine par Wang Yan 王琰 (454 ? -520 ?), actif durant les dynasties des Song du Sud (420-479) et des Qi du Sud (479-502), NdT.

15. Taishōzō, vol. 53, 459b.

16. En l'espèce, les Chroniques des sept grands temples bouddhiques (Shichidaiji nikki 七大寺日記), les Notes personnelles prises au cours du pèlerinage dans les sept grands temples bouddhiques (Shichidaiji junrei shiki 七大寺巡礼私記), ou bien encore le Recueil de récits sur les origines miraculeuses de divers temples bouddhiques (Shoji engi-shū 諸寺緑起集).

17. Umezu Jirō 梅津次郎, "Goshu shōji rinne-zu ni tsuite»五趣生死輪廻図に就いて [À propos des peintures du cycle de réincarnations dans les Cinq Voies], dans Bijutsu-shi 美術史, no 15-16, 1955 ; étude rééditée dans Emakimono-sōkō 絵巻物叢考 [Réflexions sur les rouleaux horizontaux], Tōkyō, Chūō kōron bijutsu shuppan, 1968. Miyaji Akira 宮地昭, «Shōjirin (Rokudō rinne-zu) kara kanshin Jikkai-zu e - bukkyō sekaikan o bijutsu kara yomitoku 》生死輪 (六道輪廻図) から 観心十界図へ 仏教世界観を美術から読み解く [Des cycles de réincarnations (Peintures des Six Voies) aux Mandalas des dix mondes: l'art comme mode d'expression de la vision bouddhique du monde], dans Zen-kenkyūjo kiyō 禅研究所紀要, nº 47, 2018.

18. Dans les rouleaux horizontaux japonais, les peintures sont toujours précédées d'un texte introductif, 
rédigé en langue vernaculaire (même si les sources sont chinoises) et déterminant pour l'identification des peintures, quand il a été conservé, $N d T$.

19. Les onmyō-ji étaient des fonctionnaires de l'Office de la divination à la cour impériale. Ils étaient chargés de déterminer les jours fastes et néfastes, les interdits de direction et d'interpréter les signes sortant de l'ordinaire, NdT.

20. Chaque année, au milieu du septième mois, un rituel de type matsuri se déroulait dans le sanctuaire shintō de Yasaka, ou sanctuaire de Gion, en l'honneur de la divinité Gozu-tennō, qui protège les fidèles contre les maladies. Ce matsuri aurait vu le jour en 869 , au lendemain d'une série de catastrophes qui frappa le pays, dont et notamment une terrible épidémie, $N d T$.

21. Une dhārañi est une formule incantatoire, ou "détentrice» de pouvoir, dans le bouddhisme ésotérique, $\mathrm{NdT}$.

22. Taishōzō, vol. 19, 742ab.

23. Il s'agit d'un continent situé au sud du mont Meru - l'axe du monde selon la cosmologie indienne -, où vivent les êtres humains, $N d T$.

24. La source se trouve dans les ouvrages suivants : Wang Guoliang 王國良, “Shenyi-jing yanjiu » 神異経 研究 [Recherches sur le Shenyi-jing], dans Wenshi zhexue jicheng 文史哲學集成， ${ }^{\circ} 121$, Wenshizhe chubanshe, 1985 ; Zhang Hua 張華 et al. (sélection) et Wang Genlin 王根林 et al. (commentaire), Bowuzhi (Wai qi-zhong) 博物志 (外七種) (Bowuzhi, Wai qi-zhong), Shanghai guji chubanshe, 2012.

25. En l'espèce, le recueil d'histoires étranges $\grave{A}$ la recherche des esprits (ch. Soushen-ji 捜神記), compilé par Gan Bao 干宝 (?-336) de la dynastie des Jin de l'Est (317-420), et l'ouvrage " ethnographique » Sur les coutumes et les mœurs (ch. Fengsu tongyi 風俗 通儀), rédigé par Ying Shao 應劭 (140-206) des Han postérieurs (25-220).

26. Nakano Genzō 中野玄三, Rokudō-e no kenkyū 六道絵の研究 [Recherches sur les peintures des Six Voies], Kyōto, Tankōsha, 1989.

27. Nagata Maki 永田真紀, «Kiko Shōki no zuzō no denshō to hen.yō » 騎虎鍾馗の図像の伝承と変容 $[\mathrm{La}$ transmission et l'évolution de l'iconographie de Shōki chevauchant un tigre], dans Shimao Arata 島尾新, Akiko, princesse de Mikasa 涁子女王 et Kameda Kazuko 亀田 和子 (dir.), Utsushi no chikara: sōzō to keishō no matorikusu 写しの力: 創造と継承のマトリクス [La force de la copie : matrice de création et de transmission], Kyōto, Shibunkaku shuppan, 2013.

28. The Heavenly King on the March, IX siècle, époque Tang, peinture sur soie, Londres, The British Museum, inv. 1919,0101,0.45.

29. Fondé par le moine Saichō (767-822) à son retour de Chine, ce monastère situé au nord-est de la ville de Kyōto est le plus important centre du bouddhisme Tendai au Japon, $N d T$.

30. Miyajima,1985, cité n. 5 ; Umezawa, 2014, cité n. 6.

31. Tōden-gyōhitsu 榻鴫暁筆, Ichiko Teiji 市古貞次 (éd.), Tōkyō, Miyai shoten, 1992.

32. Taishōzō, vol. 4, 523b : chapitre $\mathrm{V}$ «Compilation sur les moines bouddhistes par Dao Lüe», ch. Biqiu Dao Lüe-ji 比丘道略集, cinquième histoire.

33. Taishōzō, vol. 4, 536a : livre I, vingtième histoire.

34. Il est cependant visible pour le moine qui a renoncé au monde, NdT.

35. Fukui Rikichirō 福井利吉郎, 1960, cité n. 5. De plus, on a découvert récemment un fragment de texte introductif, semble-t-il, en lien avec des peintures des Six Voies. Ce corpus est présenté de façon détaillée par Ikeda Kazuomi 池田和臣, dans « Den Jakuren hitsu shinshutsu Jigoku-zōshi kotobagaki dankan » 伝寂連筆 新出・地獄草紙詞書断簡 [Un fragment inédit de texte introductif du Rouleau des enfers, attribué à Jakuren], dans Shūbi 聚美, nº 22, 2017. Dans cette étude, Ikeda cherche à déterminer si ce fragment ne pourrait pas correspondre à la partie perdue du texte introductif du Démon chassé de Fukuoka, mais les incohérences de contenu sont trop importantes avec le texte copié par Tanaka Shimbi. Cependant, il note leur proximité stylistique sur le plan calligraphique et suggère que le fragment inédit pourrait avoir été associé à une peinture non identifiée en lien avec la version Masuda et le Démon chassé. Ce fragment nouvellement découvert présente des êtres étranges en conversation avec des humains et on peut en inférer qu'il concerne la Voie des esprits démoniaques.

36. Toutes les traductions de sources primaires sont de notre fait, sauf précision contraire, $N d T$.

37. C'est-à-dire la résidence céleste du dieu Bishamonten, $\mathrm{NdT}$.

38. Matsuura Masaaki松浦正昭, «Bishamonten mandara to setsuwa-e » 毘沙門天曼茶羅と説話絵 [Les Mandara de Bishamonten et les peintures de récits édifiants], dans Bishamonten-zō 毘沙門天像 [Les représentations de Bishamonten], Tōkyō, Shinbundō (coll. « Nihon no bijutsu »日本の美術, vol. 315), 1992.

39. La place de la Voie des titans dans les Cinq Voies est abordée dans la note 2 de l'article d'Erika PeschardErlih intitulé "Kamakura-jidai ni okeru jigoku-e no zuzō pataan no tenkai 》 鎌倉時代における地獄絵の 図像パターンの展開 [The Evolution of the Iconographic Patterns in Paintings of the Hell during the Kamakura Period], dans Akiyama Terukazu hakase koki kinen bijutsu-shi ronbun-shū 秋山光和博士古稀記念美術史 論文集 [Articles in honor of the $70^{\text {th }}$ anniversary of Doctor Akiyama Terukazu], Kyōto, Benridō, 1991. Erika Peschard-Erlih se base également sur des docu ments en langue française à ce sujet : Paul Mus, La lumière sur les six voies, Paris, Institut d'ethnologie, 1939 ; Lin Li-Kouang, Introduction au compendium de la loi (Dharmasamuccaya), L'aide-mémoire de la Vraie Loi (Saddharma-Smrtyupasthana-sutra), Paris, AdrienMaisonneuve, 1946.

40. Taishōzō, vol. 16, 349c-350ab : chapitre XIII : «Des esprits démoniaques ».

41. Taishōzō, vol. 17, 107a.

42. Taishōzō, vol. 25, 280a.

43. Ibidem.

44. Taishōzō, vol. 25, 135bc.

45. Taishōzō, vol. 84, 38a. 
46. Pour des explications détaillées en français à propos de la version du temple Shōjuraigō-ji, consulter Erika Peschard-Erlih, "Les peintures des Enfers du Rokudo-e du monastère Shoju-raigoji », dans 共立国際 文化 [The Journal of Kyoritsu Area Studies], n 17, 2000 ; Laure Schwarts-Arenales, "À propos des Images des Six Destinées (Rokudō-e) du temple Shōjuraigōji : une introduction », dans Izumi Takeo 泉武夫, Kasuya Makoto 加須屋誠, Yamamoto Satomi 山本聡美 (dir.), Kokuhō Rokudō-e 国宝六道絵 [The Six Realms Paintings In Shōjuraigōji Temple], Tōkyō, Chūōkōron bijutsu shuppan, 2007.

47. Il s'agit d'une collection de récits édifiants compilée pendant l'ère Jishō (1177-1181) par Taira no Yasunori 平康頼 (1146-1220).

48. La citation est donnée à partir de l'édition du texte fournie dans la collection « Shin-Nihon koten bungaku taikei », vol. 40.

49. Ce passage en vers est une citation du Sūtra du Lotus, dans la traduction de Jean-Noël Robert, Paris, Fayard, 1997, p. 313-314, NdT.

50. En effet, les dieux sont d'anciens titans, NdT.

51. Il s'agit d'un poème d'amour : le terme moshiogusa 藻塩草 (《 algues marines ») désigne également en poésie des lettres d'amour. Les algues permettent de fabriquer le sel, via une succession d'opérations complexes qui provoquent de la fumée sur le bord de mer. II est donc suggéré ici que la belle est plus attirée par d'autres amants que par le poète, $N d T$.

52. Le thème du brame des daims est associé à celui de l'amant séparé de l'objet de ses vœux, NdT.

53. Il y a un jeu de mots ici, " retourner un vêtement » pouvant suggérer que le poète va rendre public des feux jusqu'ici tenus secrets, $N d T$.

54. Il s'agit d'un genre de poésies en langue japonaise qui domine largement la production classique et médiévale, $N d T$.

55. Il s'agit de poésies en langue chinoise composées par des lettrés de cour japonais. Cette production est très importante et apparaît dès le VII siècle, $N d T$.

56. Cette anthologie poétique a été élaborée par le moine Saigyō 西行 (1118-1190) au cours de la guerre civile de Genpei (1181-1185).

57. Noguchi Keiya野口圭也, «Shōjuraigō-ji-bon Rokudō-e chū Ashuradō-fuku nitsuite" 聖衆来迎寺本 『六道絵』中『阿修羅道幅』について [À propos du Rouleau de la Voie des titans des Peintures des Six Voies du Shōjuraigō-ji], dans Heian bukkyō gakkai nenpō 平安仏教学会年報, n 3, 2004 ; Kim Ingchong 金任仲, Saigyō waka to bukkyō shisō 西行和歌と仏 教思想 [La poésie de Saigyō et la pensée bouddhique], Tōkyō, Kasama shoin, 2007 ; Tamura Masahiko 田村正彦, “Saigyō Rokudō uta zakkan - San akushu no uta nitsuite» 西行「六道歌」雑感一三悪趣の歌 について [Réflexions au sujet des Poèmes sur les Six Voies de Saigyō : À propos des trois Voies mauvaises], dans Nihon bungaku kenkyū-shi 日本文学研究史, $8^{e}$ série, 2010 ; et du même auteur, Egakareru jigoku katareru jigoku 描かれる地獄語られる地獄 [Les enfers dans la peinture et la littérature], Tōkyō, Miyai shoten, 2015.
58. Épisode «La parabole des Six Voies de l'impératrice douairière Kenreimon'in » (Kenreimon'in no rokudōgatari 建礼門院の六道語り), dans la version d'Akashi Kakuichi 明石覚一 (1299-1371), coll. «Shin-Nihon koten bungaku taikei », vol. 45. "Vainqueurs cependant à Muroyama, à Mizushima et autres lieux, nos gens parais saient avoir repris un peu d'assurance quand à Ichino-tani bon nombre de ceux de notre Maison furent tués, et dès lors ils troquèrent le nōshi [la tenue de cour] et la ceinture de soie contre la cuirasse bardée de fer ; du matin jusqu'au soir sans cesse retentissaient les cris de guerre; ainsi doit être, j'imagine, la lutte des Ashura [les titans] et leur combat avec Taishakuten. » Traduction de René Sieffert, Paris, Publications orientalistes de France, 1997, p. 543, NdT.

59. « [P]erdant la vie sur le champ de bataille, né dans la Voie mauvaise des titans belliqueux [...] », édition commentée de Tomikura Tokujirō 冨倉徳次郎, Tōkyō, Iwanami bunko, 1944.

60. «Comme les hommes mourant à la pointe du sabre tombent dans la Voie des titans, tuez donc Norishige ! » Épisode «La mort de Takakura no Norishige » (Takakura no Norishige no saigo 高倉範茂の最期), version du temple Jikō-ji, coll. «Shin-Nihon koten bungaku taikei », vol. 43.

61. « Il y a fort longtemps, le roi Taishakuten fut attaqué et vaincu par le roi des titans. Il s'enfuit alors tout en haut du mont Meru. Bien que ce dernier fût fort escarpé, ses troupes s'apprêtèrent à l'escalader, innombrables comme les sables du Gange. Mais, sur cette montagne, se dit alors Taishakuten, il y a en abondance des œufs de l'oiseau garuda qui risquent d'être écrasés et détruits par la bataille. En conséquence, comme il ne voulait en aucun cas attenter à la vie, dût-il lui en coûter la sienne, il quitta le mont Meru pour se rendre dans les montagnes Cakravāḍa. Croyant alors que son ennemi revenait sur ses pas pour le poursuivre, le roi des titans s'enfuit et fut vaincu par l'armée de Taishakuten. Quel triomphe pour lui que sa vertu enjoignait à ne pas attenter la vie ! Ce seigneur, soucieux de préserver la vie des cerfs, interdit la chasse. Comment prétendre que cela ne lui serait pas profitable? » Épisode "L'Histoire du combat entre Taishaku et le roi des titans » (Teishaku, shura-ō tatakahi no koto 帝釈・修羅王たつかひの事), coll. "Nihon koten bungaku taikei », vol. 88.

62. "Les gens qui voyaient les femmes et les enfants errant dans la fumée de l'incendie et qui, sous le coup de la précipitation, se jetaient dans leur fuite éperdue au sein des flammes et dans les fossés, se disaient "Est-ce cela le spectacle des troupes des titans, chassées par les seigneurs du ciel, s'écroulant dans le feu sous la menace des sabres et des lances, ou encore celui des criminels des enfers poursuivis par les vociférations gardiens infernaux et tombant dans du fer en fusion?" " Épisode " Les troupes de Kamakura aux prises avec un incendie, et les exploits des Nagasaki père et fils " (Kamakura hei kaji tsuki Nagasaki-fushi buyū no koto 鎌倉兵火事付長崎父子武勇事), Hyōdo Hiromi 兵藤裕己 (éd.), vol. 2, Tōkyō, Iwanami bunko, 2014-. 